\title{
Dopamine Terminals in the Rat Prefrontal Cortex Synapse on Pyramidal Cells that Project to the Nucleus Accumbens
}

\author{
David B. Carr, Patricio O'Donnell, J. Patrick Card, and Susan R. Sesack \\ Departments of Neuroscience and Psychiatry, University of Pittsburgh, Pittsburgh, Pennsylvania 15260
}

\begin{abstract}
Afferents to the prefrontal cortex (PFC) from dopamine neurons in the ventral tegmental area have been implicated in working memory processes and in the pathogenesis of schizophrenia. Previous anatomical investigations have demonstrated that dopamine terminals synapse on dendritic spines and shafts of pyramidal cells in the PFC. Moreover, neurochemical and physiological studies suggest that dopamine modulates the activity of PFC neurons that project to the nucleus accumbens. However, whether this modulation involves direct synaptic input to cortico-accumbens projection neurons has not been determined. To address this question, retrograde transport of an attenuated strain of pseudorabies virus (PRV) from the nucleus accumbens was combined with immunoperoxidase labeling of tyrosine hydroxylase $(\mathrm{TH})$ to identify dopamine terminals in the PFC. At survival times $<48 \mathrm{hr}$, extensive dendritic distribution of immunogold labeling for PRV was observed in cortico-
\end{abstract}

The mesocortical dopamine (DA) system has received considerable attention, because of its proposed role in the cognitive functions subserved by the prefrontal cortex (PFC) (GoldmanRakic, 1992). The distribution of cortical DA fibers has been described in rodents as well as in human and nonhuman primates, using several histochemical techniques (Berger et al. 1976; Descarries et al. 1987; Lewis and Sesack, 1997). At the ultrastructural level, DA terminals synapse on the dendritic tree of both pyramidal cells and local circuit neurons (Séguéla et al. 1988; Goldman-Rakic et al. 1989; Sesack et al. 1995b). Recent evidence suggests that DA terminals selectively synapse on specific classes of local circuit neurons, as categorized by their content of calcium-binding proteins (Sesack et al. 1995a; Sesack et al. 1998). However, the subpopulations of pyramidal cells that are synaptically innervated by DA have not been determined.

One of the principal efferents of the PFC is its projection to the nucleus accumbens (NAc) (Sesack et al. 1989). The PFCaccumbens projection is part of a multisynaptic processing loop that also involves the ventral pallidum and mediodorsal thalamus (Alexander et al. 1990; Groenewegen and Berendse, 1994; O'Donnell et al. 1997). This circuit plays a role in motivated and cognitive behaviors and has been implicated in the etiology of schizophrenia and other neuropsychiatric disorders (Weinberger,

\footnotetext{
Received Aug. 6, 1999; revised Sept. 30, 1999; accepted Oct. 4, 1999.

This work was supported by United States Public Health Service Grants MH11368 (D.B.C.), MH53574 (J.P.C.), and MH50314 (S.R.S.).

Correspondence should be addressed to Dr. Susan R. Sesack, Department of Neuroscience, 446 Crawford Hall, University of Pittsburgh, Pittsburgh, PA 15260. E-mail: Sesack@brain.bns.pitt.edu.

Dr. O'Donnell's present address: Department of Pharmacology and Neuroscience, Albany Medical College, 47 New Scotland Avenue, Albany, NY 12208-3479.

Copyright (C) 1999 Society for Neuroscience 0270-6474/99/1911049-12\$05.00/0
}

accumbens neurons. However, evidence consistent with transsynaptic passage of PRV within this timeframe was observed only rarely. When examined at the electron microscopic level, immunogold labeling for PRV was localized to neuronal somata, proximal and distal dendrites, and dendritic spines. Some of these dendritic processes received symmetric synaptic input from TH-immunoreactive terminals. These data represent the first demonstration of dopamine synaptic contacts onto an identified population of pyramidal cells in the PFC. The findings have important implications for understanding how dopamine modulates cortical outflow to limbic regions in normal brain and pathological states such as schizophrenia.

Key words: prefrontal cortex; dopamine; nucleus accumbens; prelimbic cortex; infralimbic cortex; ultrastructure; schizophrenia

1987; Csernansky et al. 1991; Grace, 1991). Anatomical and electrophysiological studies have demonstrated that PFC input to spiny projection neurons in the NAc is subject to modulation by mesolimbic DA afferents (Sesack and Pickel, 1992; O'Donnell and Grace, 1994; Harvey and Lacey, 1996).

Whether DA afferents also modulate PFC-accumbens transmission by synapsing on PFC neurons that project to the NAc is not known. However several lines of evidence suggest that such synapses may occur. The projection from the PFC to the NAc arises from pyramidal cells located primarily in layer V (Brog et al. 1993; Pinto et al. 1997), which, along with layer VI, contains the highest concentration of DA terminals in the rat PFC (Lindvall and Björklund, 1984; Descarries et al. 1987). Electrophysiological studies also show that PFC pyramidal cells projecting to the NAc respond to applied DA or stimulation of the ventral tegmental area (VTA) (Jay et al. 1995; Yang and Seemans, 1996). Furthermore, mRNA for D1 and D2 DA receptors has been localized in pyramidal neurons retrogradely labeled from the striatum (Gaspar et al. 1995). However, DA may exert at least some of its actions via local circuit neurons (Sesack et al. 1995b) or through extrasynaptic mechanisms (Smiley et al. 1994), making it unclear whether PFC-accumbens neurons receive direct synaptic contacts from DA terminals.

To examine this question, a method is required that will selectively label different populations of pyramidal cells. However, unlike local circuit neurons, pyramidal cells are not easily classified by histochemical content. Pyramidal cells can be classified based on the target of their main projection axon, as determined by retrograde tract tracing. However, in tissue prepared for electron microscopy, most conventional retrograde tracers are detected primarily in the soma and proximal dendrites and rarely in 
the distal dendrites and spines where DA terminals synapse (Séguéla et al. 1988; Goldman-Rakic et al. 1989; Sesack et al. 1995b).

The recent introduction of neurotrophic viruses for use as neuronal tracing substances allows for retrograde labeling of PFC pyramidal neurons that extends into their distal processes. One strain of virus, pseudorabies virus (PRV), is avidly taken up by axon terminals and transported retrogradely to the soma where it replicates to form infectious progeny. During the course of infection, viral particles and virally encoded proteins are transported throughout the dendritic tree, where viral particles pass transneuronally at sites of synaptic contact in a process that leaves viral membrane at both presynaptic and postsynaptic sites (Card, 1998a). This property of PRV produces extensive labeling of the dendritic tree of infected neurons and permits visualization of identified synaptic contacts onto distal processes. In the present study, we have applied the viral retrograde tracing method with dual-label immunocytochemistry and electron microscopy to determine if PFC pyramidal neurons that project to the NAc receive synaptic contact from DA terminals.

\section{MATERIALS AND METHODS}

$P R V$ injection. The strain of virus that was used in this experiment (PRV-Bartha) is an attenuated strain of pseudorabies virus that was initially developed as a swine vaccine (Bartha, 1961). PRV-Bartha replicates efficiently in the rodent CNS and has been used to demonstrate multisynaptic circuitry in a variety of neural systems (for review, see Card, 1998a,b). Procedures for growing and harvesting the virus have been described in detail elsewhere (Enquist and Card, 1996). PRV was stereotaxically injected via a $0.5 \mu \mathrm{l}$ syringe into the medial NAc of 27 male Sprague Dawley rats under chloral hydrate anesthesia $(420 \mathrm{mg} / \mathrm{kg}$, i.p.). The coordinates for the injection were $1.3 \mathrm{~mm}$ anterior to bregma, $1.3 \mathrm{~mm}$ lateral to the midline, and $7.6 \mathrm{~mm}$ ventral to the skull surface, according to the atlas of Paxinos and Watson (1986). For each animal, $50-150 \mathrm{nl}$ of PRV $\left(1.4 \times 10^{9}\right.$ plaque-forming units $\left./ \mathrm{ml}\right)$ was injected at a rate of $10 \mathrm{nl} / \mathrm{min}$, and the syringe was left in place for 5 min after completion of the injection to prevent reflux of the virus up the cannula track. In compliance with the regulations stated in Health and Human Services Publication No. 88-8395, PRV injections were performed in a Biosafety Level 2 containment facility, and animals were housed in this facility until they were killed by aldehyde perfusion. After a $24-60 \mathrm{hr}$ survival period, animals were deeply anesthetized with Nembutal (100 $\mathrm{mg} / \mathrm{kg}$, i.p.) and perfused through the aortic arch with the following solutions: (1) $10 \mathrm{ml}$ of $0.9 \%$ saline containing $1000 \mathrm{U} / \mathrm{ml}$ of heparin, (2) $50 \mathrm{ml}$ of $3.75 \%$ acrolein and $2 \%$ paraformaldehyde in $0.1 \mathrm{M}$ phosphate buffer (PB), and (3) $2 \%$ paraformaldehyde in $0.1 \mathrm{M} \mathrm{PB}$. The brains were removed, and 5-6 mm coronal blocks containing the PFC and NAc were post-fixed in the last fixative for $30 \mathrm{~min}$. Vibratome $(50 \mu \mathrm{m})$ sections through the PFC were processed for immunocytochemical detection of tyrosine hydroxylase (TH) and PRV.

Immunoperoxidase-immunogold dual-label histochemistry. A duallabeling method was used in which dopamine terminals were visualized by peroxidase immunocytochemistry for $\mathrm{TH}$, while retrogradely transported PRV was visualized by pre-embedding immunogold labeling with silver intensification. Briefly, vibratome sections were incubated for 30 min in $1 \%$ sodium borohydride in $0.1 \mathrm{M} \mathrm{PB}$ to improve immunocytochemical labeling (Leranth and Pickel, 1989). After rinses in $0.1 \mathrm{M} \mathrm{PB}$ and $0.1 \mathrm{~m}$ Tris-buffered saline (TBS), sections were incubated for $30 \mathrm{~min}$ in blocking solution containing 3\% normal goat serum and $1 \%$ bovine serum albumin in TBS. To enhance antibody penetration, blocking solution contained $0.04 \%$ Triton X-100 (Sigma, St. Louis, MO) for electron microscopic examination or $0.2 \%$ for light microscopy. Sections were then incubated for $12-15 \mathrm{hr}$ in blocking solution containing polyclonal antiserum raised in rabbit against PRV (1:1000; gift of Dr. L. W. Enquist) and mouse monoclonal antibody generated against TH (1:50; Boehringer Mannheim, Indianapolis, IN). For peroxidase localization of $\mathrm{TH}$, sections were rinsed in TBS and then incubated in biotinylated horse anti-mouse antiserum (1:400; Vector Laboratories, Burlingame, CA) for $30 \mathrm{~min}$. Sections were again rinsed in TBS followed by a $30 \mathrm{~min}$ incubation in avidin-biotin peroxidase complex (1:200; Vectastain Elite kit; Vector Laboratories). The bound peroxidase was visualized by incubat- ing the sections in $0.022 \%$ diaminobenzidine and $0.003 \%$ hydrogen peroxide in TBS for $2-5$ min. For immunogold localization of PRV, sections were incubated for $30 \mathrm{~min}$ in a blocking solution containing $0.8 \%$ bovine serum albumin and $0.1 \%$ fish gelatin in $0.01 \mathrm{M}$ PBS. Sections were then incubated in blocking solution that also contained goat anti-rabbit antiserum conjugated to $1 \mathrm{~nm}$ gold particles (1:50; Goldmark Biologicals). After rinses in blocking solution and PBS, the size of the gold particles was subsequently enhanced by incubation in silver solution (Amersham, Arlington Heights, IL) for 5-7 min. All incubations and rinses were performed at room temperature under constant gentle agitation.

For single label light microscopic peroxidase visualization of PRV, tissue sections were treated as described above, using a dilution of $1: 10,000$ for the rabbit anti-PRV primary antibody and substituting biotinylated goat anti-rabbit antiserum (Jackson ImmunoResearch, West Grove, PA) in the secondary antibody step.

Tests for the specificity of the PRV-Bartha antiserum have been described elsewhere (Card and Enquist, 1994). Tests for the specificity of the TH antibody (e.g., Western blot analysis) have been performed by the supplier. TH rather than DA antibody was used to label DA terminals within the PFC because DA antibodies are incompatible with acrolein fixation, which is optimal for PRV. Moreover, considerable evidence indicates that TH antibodies label primarily DA rather than norepinephrine (NE) terminals within the cortex (for review, see Lewis and Sesack, 1997). In addition, the tissue examined was taken exclusively from layers $\mathrm{V}$ and VI of the medial PFC, in which the density of DA terminals is higher than for NE afferents (Descarries and Lapierre, 1973; Lindvall and Björklund, 1984; Descarries et al. 1987; Audet et al. 1988). Finally, the frequency with which DA terminals form distinct synaptic contacts is also higher than the frequency observed for NE terminals in the rat cortex (93 vs 17\%, respectively) (Séguéla et al. 1988, 1990; Descarries and Umbriaco, 1995). Thus, the available evidence suggests that the majority of TH-labeled terminals observed in this study, particularly those forming distinct synaptic junctions, represent DA rather than NE terminals.

Immunofluorescence histochemistry. As part of a time course analysis of PRV infection, dual-immunofluorescence detection of PRV and GABA were performed to determine the duration of first-order pyramidal neuronal infection required to secondarily infect GABA-containing local circuit neurons that synapse on pyramidal cells within the PFC. In this case, sections immediately adjacent to those prepared for electron microscopy were incubated in blocking solution containing polyclonal rabbit anti-PRV antiserum (1:1000) and mouse monoclonal anti-GABA antibody (1:1000; Sigma) for $48 \mathrm{hr}$ at $4^{\circ} \mathrm{C}$. After thorough rinsing in TBS, sections were incubated for $1 \mathrm{hr}$ in blocking solution containing CY2conjugated donkey anti-rabbit and CY3-conjugated donkey anti-mouse antisera (1:400; Jackson ImmunoResearch). Sections were then rinsed and prepared for light microscopic examination as described below.

Light and electron microscopy. Sections for light microscopy were mounted on glass slides, dehydrated, and coverslipped with Krystalon (Harleco). Sections for electron microscopy were post-fixed for $1 \mathrm{hr}$ in $2 \%$ osmium tetroxide in $0.1 \mathrm{M} \mathrm{PB}$, dehydrated through successive alcohols and propylene oxide and embedded in Epon-812 (Electron Microscopy Sciences). Ultrathin sections were taken from the outer surface of the tissue and collected on copper mesh grids. Sections were counterstained with uranyl acetate and lead citrate and examined with either a Zeiss 902 or Joel 100CX transmission electron microscope.

Electron microscopic examination. Ultrathin sections were taken from vibratome sections through the deep layers (V-VI) of the prelimbic and infralimbic cortices, as defined by Krettek and Price (1977). Within single, nonconsecutive sections, tissue was examined at $12,000 \times$ magnification along the Epon/tissue interface, the area of maximum antibody penetration. All synaptic contacts and nonsynaptic appositions between TH-labeled terminals and PRV-labeled profiles were quantified at this magnification (Table 1) and then photographed at a magnification of $19,000-20,000 \times$. A total of $1,477,713 \mu \mathrm{m}^{2}$ of tissue was examined from four animals chosen for ultrastructural analysis (four to six vibratome sections per animal). These subjects were chosen because they exhibited the best combination of immunocytochemical labeling and ultrastructural preservation.

Neuronal elements were defined according to the criteria of Peters et al. (1991). Axon terminals contained numerous synaptic vesicles and were at least $0.2 \mu \mathrm{m}$ in diameter. Cell bodies were identified by the presence of a nucleus. Dendritic shafts were postsynaptic to axon terminals, had regular profiles, and contained mitochondria, microtubules, 
Table 1. Associations between dopamine terminals and corticoaccumbens pyramidal cells in the rat prefrontal cortex

Area of tissue examined containing both $\mathrm{TH}$ and PRV-IR structures ${ }^{a}$

Number of TH-IR terminals in the same field as PRV-IR structures

$583,073 \mu \mathrm{m}^{2}$

Number of TH-IR terminals in contact $^{b}$ with PRV-IR dendrites and spines

Number of TH-IR terminals synapsing on PRV-IR dendrites and spines
${ }^{a}$ See Materials and Methods.

${ }^{b}$ Includes synapses and nonsynaptic appositions.

and/or endoplasmic reticulum. Dendritic spines were also postsynaptic to axon terminals but were typically smaller and lacked these intracellular organelles. Glial processes contained clear cytoplasm and exhibited irregular contours that conformed to the shapes of surrounding neuronal elements. Asymmetric synapses (Gray's type I; Gray, 1959) were defined by thickened postsynaptic densities, whereas symmetric synapses exhibited thin postsynaptic densities. Synapses made by TH-labeled terminals typically lacked an appreciable postsynaptic density and were thin, being observed only in one or two consecutive serial sections. Thus, the widened spacing of parallel apposed membrane surfaces, as well as the presence of intercleft filaments (Peters et al. 1991), were often the only recognizable synaptic features made by TH-labeled terminals. This classification of synapses made by $\mathrm{TH}$ - and/or DA-labeled terminals has been applied to previous descriptions of catecholamine synapses in the cortex (Séguéla et al. 1988, 1990; Smiley and Goldman-Rakic, 1993; Sesack et al. 1995b; Carr and Sesack, 1996).

\section{RESULTS}

\section{Light microscopy}

Within the NAc, PRV injection sites were circumscribed, with viral immunoreactivity largely confined to the area immediately adjacent to the injection cannula (Fig. $1 A$ ). Only those animals in which PRV injection was within the medial NAc and did not infringe on adjacent structures were included in this study. Injections typically included portions of both the core and shell subdivisions of the NAc, and no attempts were made in this study to differentiate between these subregions. After PRV injection into the medial NAc, numerous pyramidal neurons were extensively labeled within the PFC (Fig. 1B). Consistent with previous observations using conventional tracers, the majority of PRVinfected neurons were located in layer $\mathrm{V}$ of the prelimbic and infralimbic cortices (McGeorge and Faull, 1989; Groenewegen et al. 1990; Brog et al. 1993). Within infected cortico-accumbens neurons, immunoreactivity for PRV was extensively distributed throughout the soma and dendritic tree (Fig. 1B).

To avoid false-positive results, it was necessary to ensure that viral immunoreactivity in tissue processed for electron microscopy was confined to first-order neurons and did not spread to neurons that synapse on the first-order cells. To find this optimal postinoculation survival period, a thorough temporal analysis of the distribution and extent of PRV labeling was performed. This temporal analysis revealed that a survival period of $36-48 \mathrm{hr}$ was optimal to yield maximal labeling of cortico-accumbens neurons without significant apparent second-order infection. Animals sacrificed 24-30 hr after PRV infection did not exhibit any PRV immunolabeling within the PFC, indicating that this time period was necessary for virions to be transported from the NAc and to begin replication. Animals with postinoculation periods $>48 \mathrm{hr}$ exhibited signs of advanced viral infection typified by the presence of immunoreactive glia surrounding densely labeled neu- rons. Within the $36-48 \mathrm{hr}$ postinoculation period, the pattern of PRV labeling seen within the PFC was consistent with results obtained for this pathway using conventional tracers (McGeorge and Faull, 1989; Brog et al. 1993), i.e., viral immunoreactivity was largely confined to layer $\mathrm{V}$ of the prelimbic and infralimbic cortices. Only with survival periods $>48 \mathrm{hr}$ was a more extensive pattern of infection observed, with infection spreading into superficial layers and into adjacent cortical regions.

Observations in tissue processed for dual-immunofluorescence localization of PRV and GABA also indicated that a 36-48 hr postinfection period resulted in labeling of mainly first-order neurons. As GABA-containing local-circuit neurons synapse on the soma and proximal dendrites of pyramidal neurons, these cells are likely to be the first population of neurons subject to trans-synaptic infection by PRV. At postinoculation intervals $<48$ hr, all PRV-labeled neurons were immunonegative for GABA. In animals surviving $48 \mathrm{hr}$ after infection, only $2.5 \%$ (10 of 403) of all PRV-labeled neurons were also labeled for GABA. Furthermore, within these dual-labeled cells, PRV immunoreactivity was largely confined to the soma and did not extend out into the dendritic tree, consistent with an early stage of infection (Fig. 2). As DA synaptic contacts target distal portions of the dendritic tree of both pyramidal and local- circuit neurons within the PFC (Van Eden et al. 1987; Séguéla et al. 1988; Goldman-Rakic et al. 1989; Smiley and Goldman-Rakic, 1993; Sesack et al. 1995b) it is unlikely that the rare infection of second-order neurons in animals with $48 \mathrm{hr}$ survival periods contributed to the observed synaptic contacts of DA terminals onto PRV-immunoreactive profiles. It should be noted that the use of sections fixed with acrolein contributed to a certain degree of background fluorescence. However, we felt it essential to perform these control experiments in tissue from the same animals immediately adjacent to those examined by electron microscopy. Furthermore, despite this background fluorescence, dual labeling for GABA and PRV was observed in few neurons and only at survival periods $>48 \mathrm{hr}$.

\section{Electron microscopy}

\section{Characterization of PRV labeled profiles in the PFC}

Within the deep layers of the medial PFC, immunogold labeling for PRV was observed in neuronal somata, dendrites, and dendritic spines. Within somata of infected cortico-accumbens neurons, PRV immunoreactivity was densely distributed throughout the nucleus and cytoplasm (Fig. $3 A$ ). Viral particles were also observed in the somata of infected neurons (Fig. 3B). PRVimmunoreactive somata typically exhibited smooth uninvaginated nuclear envelopes and received input from unlabeled terminals forming exclusively symmetric synaptic contacts. These morphological characteristics are consistent with PRV labeling of pyramidal projection neurons (DeFelipe and Fariñas, 1992).

The extensive labeling of the dendritic tree by PRV observed at the light microscopic level was also observed in material prepared for electron microscopic investigation, as viral immunoreactivity was observed in both large and small caliber dendrites as well as in dendritic spines (Figs. 4, 5). A proximal to distal gradient of labeling was observed with the greatest density of immunogold labeling for PRV present in the somata and proximal dendrites of infected neurons and decreasing density in more distal dendrites and dendritic spines. Dendrites containing gold-silver labeling for PRV typically exhibited smooth contours, received sparse innervation from unlabeled terminals, and often gave rise to dendritic spines (Figs. 4, 5). These characteristics are consistent with PRV 

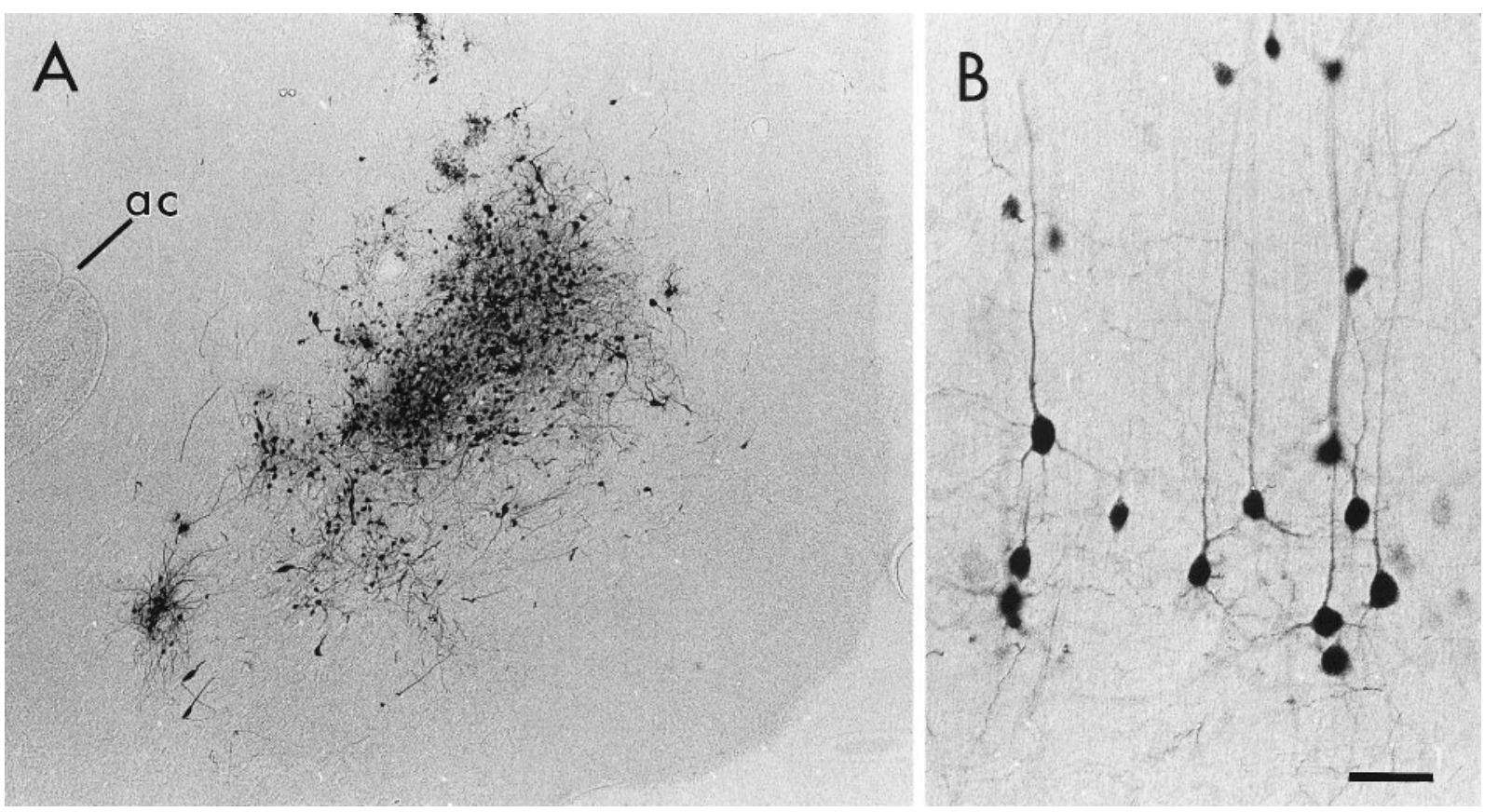

Figure 1. Light micrographs of a representative PRV injection in the NAc $(A)$ and the resulting labeling of pyramidal neurons within the PFC ( $B)$. In $A$, the PRV injection is centered between the anterior commissure $(a c)$ and the medial surface of the hemisphere. In $B$, many pyramidal neurons and their apical and basilar dendrites are extensively labeled after an injection of PRV into the NAc. Medial is toward the top, and dorsal is toward the left. Scale bar: $A, 160 \mu \mathrm{m} ; B, 40 \mu \mathrm{m}$.
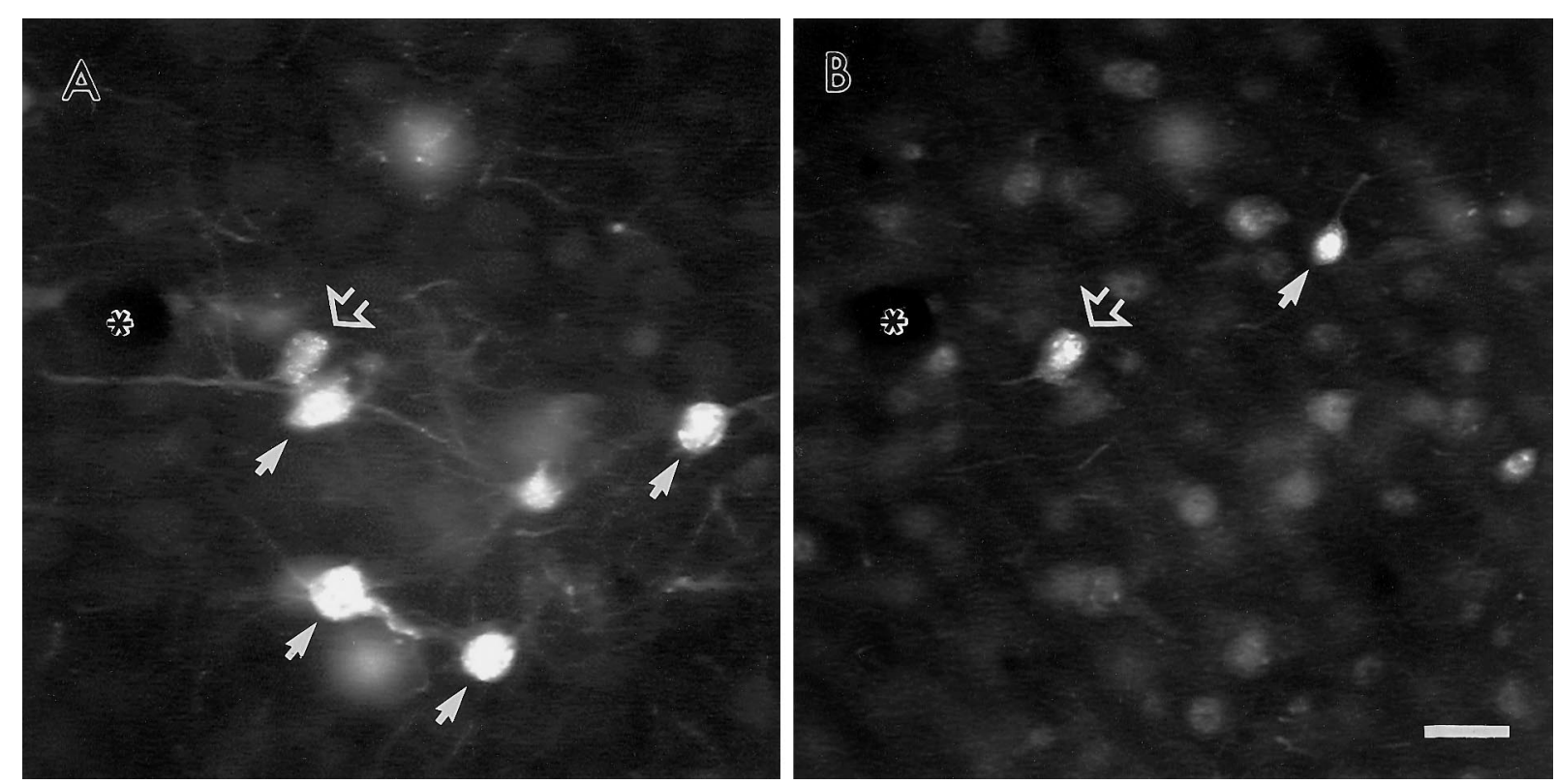

Figure 2. Fluorescence micrographs of the same coronal section through the PFC showing the distribution of neurons labeled for either PRV ( $A$ ) or GABA $(B) 48 \mathrm{hr}$ after an injection of PRV into the NAc. Within this field, most neurons contain labeling for either PRV or GABA (small arrows), but not both markers. One neuron adjacent to a small blood vessel (asterisk) contains labeling for both markers (open arrow). Note the lighter fluorescence signal and limited dendritic labeling of the dual-labeled neuron compared with other PRV-labeled neurons within the same field. Scale bar, $20 \mu \mathrm{m}$.

immunolabeling of dendrites and dendritic spines of pyramidal projection neurons (DeFelipe and Fariñas, 1992).

\section{Relationship between PRV-and TH-labeled processes}

In tissue immunolabeled for both $\mathrm{TH}$ and PRV, TH-labeled terminals were frequently observed in the same area of neuropil as PRV-labeled dendrites and dendritic spines. Furthermore,
TH-labeled terminals were often directly apposed to PRV-labeled structures (Figs. 6-8). To quantify this observation, it was noted for each TH-labeled terminal and PRV-immunoreactive structure observed in the same photographic frame (area of frame $=32.5$ $\mu \mathrm{m}^{2}$ at a magnification of $\left.12,000 \times\right)$, whether the $\mathrm{TH}$-labeled terminal directly contacted a PRV-labeled dendrite or spine. Within $583,073 \mu \mathrm{m}^{2}$ of tissue analyzed in this manner $16 \%$ (106 


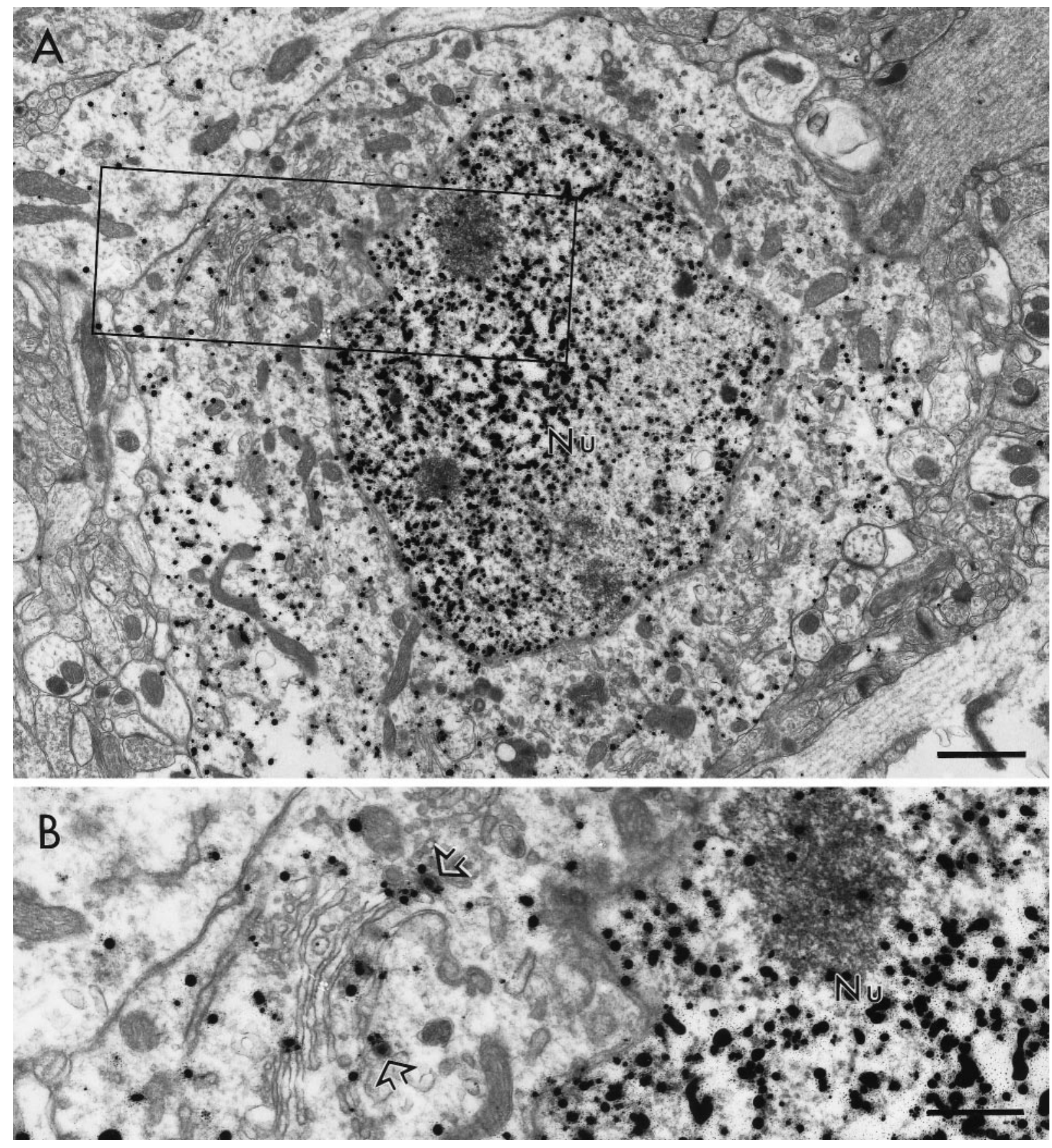

Figure 3. Electron micrographs of the rat PFC showing the distribution of immunogold-silver labeling for PRV within the somata of a corticoaccumbens neuron. In $A$, immunogold-silver particles are distributed throughout the nucleus $(\mathrm{Nu})$ and cytoplasm. The area outlined corresponds to the field shown at higher magnification in $B$. At this higher magnification, immunogold-silver particles can be seen within the nucleus and in association with the membrane envelope of virions (open arrows) and other membranous organelles. Scale bar: $A, 1 \mu \mathrm{m} ; B, 0.5 \mu \mathrm{m}$.

of 674) of TH-labeled terminals were in direct contact with PRV-labeled structures. TH-labeled terminals also frequently contacted unlabeled dendrites or dendritic spines in the vicinity of PRV-labeled structures. In some cases, the contacts made by TH-labeled terminals were clearly synaptic, as characterized by widened spacing of parallel apposed membrane surfaces as well as the presence of intercleft filaments (Fig. 8). In other cases, TH-labeled terminals were apposed to PRV-labeled and unlabeled dendrites and dendritic spines without forming clear synaptic specializations (Figs. 6, 7). In many instances, the PRVimmunoreactive spines and dendrites contacted by TH-labeled terminals also received synaptic input from unlabeled terminals forming symmetric (Fig. 6B) or asymmetric synapses (Fig. 7). This was particularly the case for PRV-labeled spines, which, as expected, each received an asymmetric synapse on the head in close proximity to the contact formed by the TH-labeled terminal (Fig. 7).

\section{DISCUSSION}

These data represent the first direct demonstration of DA synapses onto an identified population of pyramidal neurons in the rat PFC. The finding that DA terminals synapse onto PFC neu- 


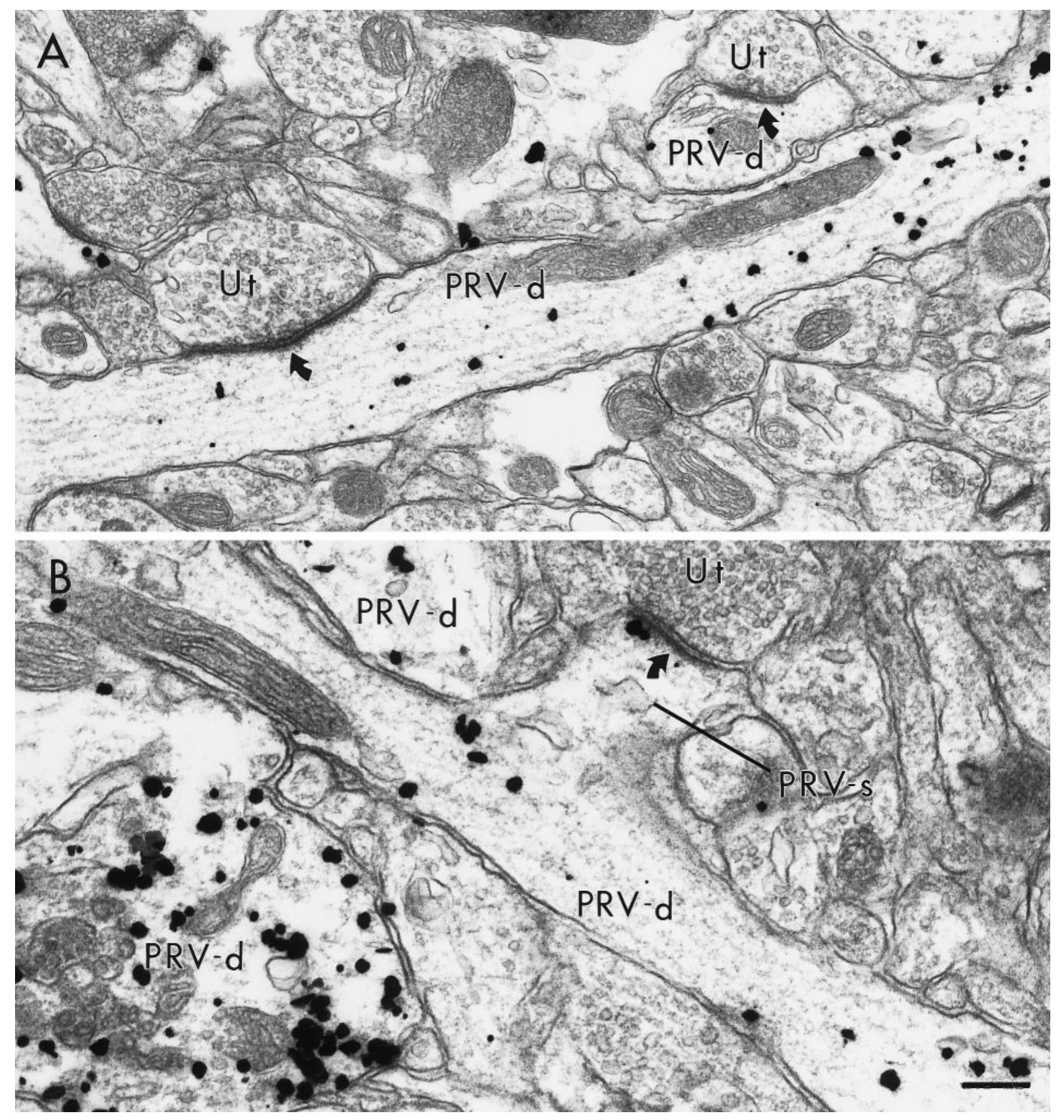

Figure 4. Electron micrographs showing dendritic shafts and spines containing gold-silver immunoreactivity for PRV. In $A$, two PRV-labeled dendrites $(P R V-d)$ receive asymmetric synapses (curved arrows) from unlabeled terminals $(U t)$. In $B$, a labeled dendritic spine (PRV-s) emanates from a PRV-labeled dendrite. The labeled spine receives an asymmetric synapse from an unlabeled terminal. Two other PRV-labeled dendrites are also present in this field. Scale bar, $0.25 \mu \mathrm{m}$.

rons that project to the NAc is consistent with neurochemical and electrophysiological studies demonstrating DA modulation of cortico-accumbens transmission and further emphasizes the direct and synaptic nature of this modulation. Finally, the results demonstrate that retrograde transport of PRV represents a novel approach to the identification of postsynaptic targets of DA axons that synapse onto the distal dendrites of cortical cells.

\section{Relationship between DA terminals and cortico- accumbens neurons in the PFC}

The ultrastructural characteristics of TH-labeled terminals identified within the PFC in this study are consistent with previous observations that the primary targets of DA terminals are distal dendrites and dendritic spines (Van Eden et al. 1987; Séguéla et al. 1988; Goldman-Rakic et al. 1989; Smiley and Goldman-Rakic, 1993; Sesack et al. 1995b). The results of this investigation provide the first direct evidence that some of these distal dendrites and spines arise from pyramidal neurons that project to the NAc. In this regard, it is important to address the specificity of PRV labeling and whether the virus is potentially taken up by fibers of passage. Previous studies have shown that viral uptake is greatest into axon terminals and astrocytes (Vahlne et al. 1978, 1980), and that virions are not likely to be taken up by intact fibers of passage 

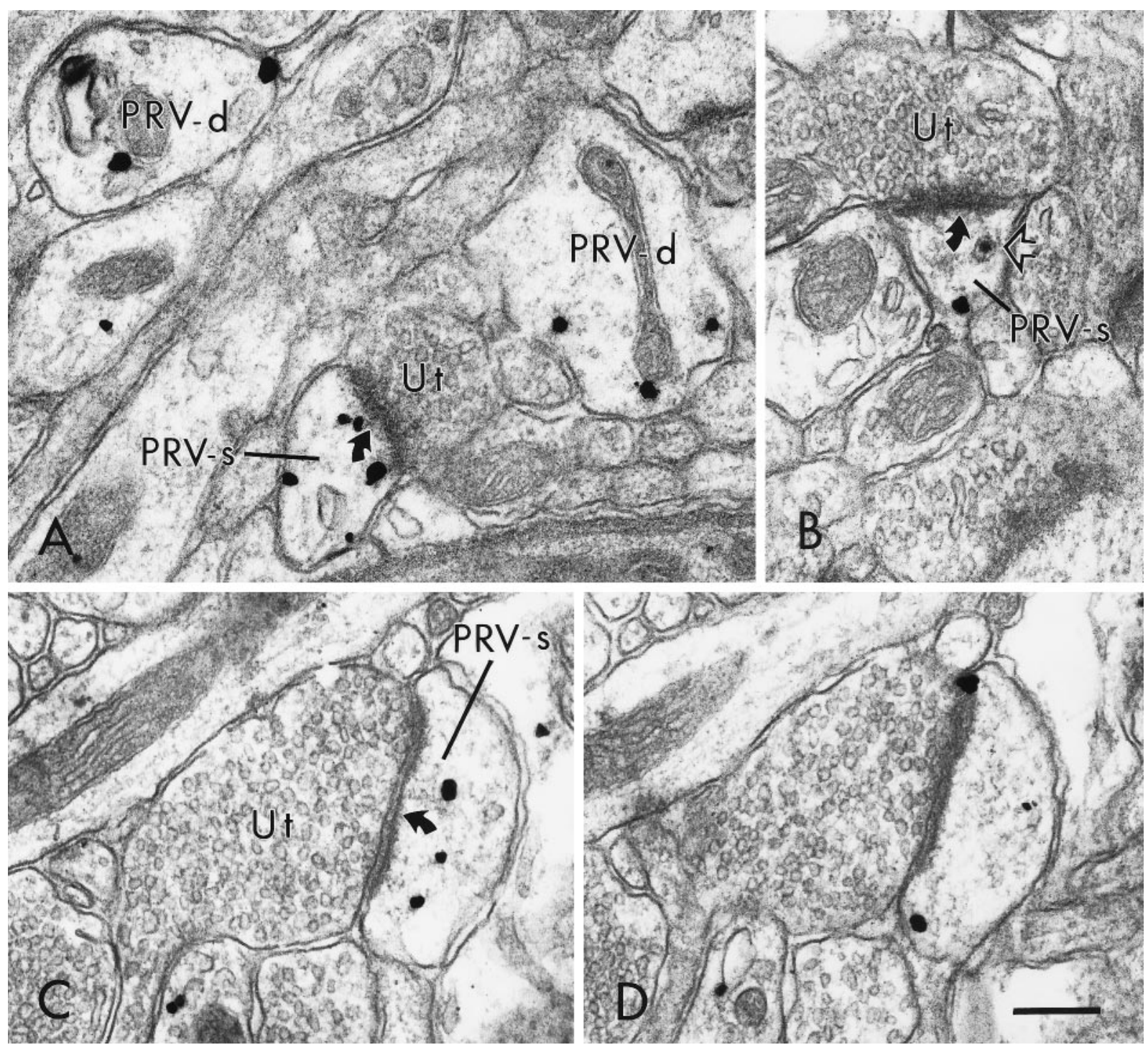

Figure 5. Electron micrographs showing the distribution of PRV immunoreactivity within distal dendrites and dendritic spines within the PFC. In $A$, viral immunolabeling is present in two small caliber dendritic shafts $(P R V-d)$ and a dendritic spine $(P R V$-s). The labeled spine receives an asymmetric synapse (curved arrow) from an unlabeled terminal (Ut). In $B$, an unlabeled terminal forms an asymmetric synapse on a dendritic spine that contains both an immunogold particle and a virion (open arrow). In $C$ and $D$, a PRV-labeled dendritic spine shown in serial sections contains several immunogold-silver particles and receives an asymmetric synapse from an unlabeled terminal. Scale bar, $0.25 \mu \mathrm{m}$.

(O’Donnell et al. 1997). Furthermore, although some PFC efferents may pass through the NAc to target more caudal structures, the majority of corticof ugal axons pass more dorsally through the striatum (Sesack et al. 1989). Finally, our temporal analysis and control experiments revealing no significant second order infection of GABA cells before $48 \mathrm{hr}$ support the specificity of PRV labeling to first order neurons. Thus, the data are most consistent with synaptic input by DA terminals to PFC pyramidal neurons that project to the NAc.

Given that the tissue sampled in this study was taken from layers $\mathrm{V}$ and VI, it is likely that the majority of the observed PRV-labeled profiles contacted by DA terminals arise from the basilar tree of cortico-accumbens neurons (DeFelipe and Fariñas, 1992), although contacts onto branches of the apical tree cannot be excluded. Although this issue has not been examined in the rodent cortex, a study by Goldman-Rakic and colleagues (Krimer et al. 1997) has reported that DA terminals within the primate
PFC contact both the basilar and apical dendrites of pyramidal neurons.

Although these results demonstrate that DA terminals within the PFC contact the dendrites and spines of pyramidal neurons that project to the NAc, currently available methods cannot provide an accurate estimate of the proportion of DA terminals that specifically contact this population. The observed synaptic frequency reported here is likely to be an underestimation for several reasons. First, the synapses that are formed by DA terminals typically lack an appreciable postsynaptic density and are only observed in one or two consecutive serial sections (Séguéla et al. 1988). According to data by Descarries and colleagues (Séguéla et al. 1988), as many as 9-12 serial sections through each DA terminal are required to observe all definitive synaptic contacts. Because such an extensive serial section analysis was not conducted in this study, the proportion of DA contacts with PRV-labeled profiles that represent distinct synapses was proba- 

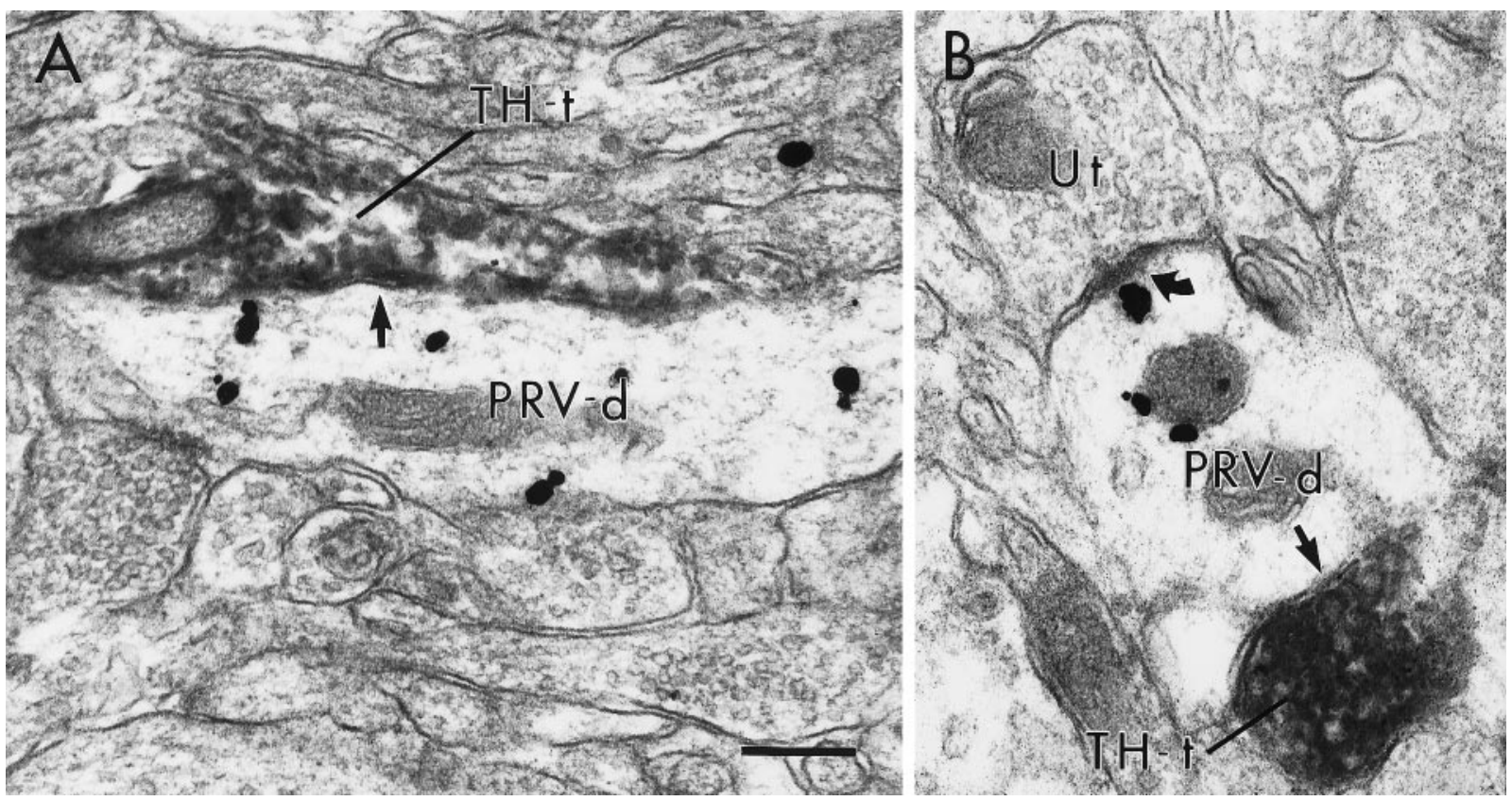

Figure 6. Electron micrographs of PRV-labeled dendrites contacted (straight arrows) by TH-immunoreactive terminals (TH-t) within the PFC. In $A$ and $B$, PRV-labeled dendrites are contacted by TH-labeled terminals without forming distinct synaptic specializations. The PRV-labeled dendrite in $B$ also receives an asymmetric synapse (curved arrow) from an unlabeled terminal (Ut). Scale bar, $0.25 \mu \mathrm{m}$.

bly underestimated. In addition, the relatively small PRV injection sites make it unlikely that all PFC-accumbens neurons were labeled. Finally, although PRV labeling was extensive within PFC-accumbens neurons, it is unlikely that this labeling filled each neuron in its entirety. For example, some spines contained only a single gold particle, despite their clearly arising from infected dendrites, as evidenced by the presence of viral particles (Fig. 5B). Thus, it is likely that some TH-labeled terminals contacted dendrites and spines arising from cortico-accumbens neurons that contained either low or undetectable levels of PRV immunoreactivity.

The observation that DA terminals targeting corticoaccumbens neurons converged with presumed excitatory inputs forming asymmetric synapses is consistent with previous observations of synaptic convergence involving DA axons in cortical structures (Séguéla et al. 1988; Goldman-Rakic et al. 1989; Carr and Sesack, 1996). Such "triadic" arrangements provide anatomical substrates for the known modulation of glutamatergic transmission by DA (Cepeda et al. 1992). Thus, the present findings suggest that DA modulates the activity of cortico-accumbens neurons, both via direct actions and by the regulation of excitatory drive to these cells.

In interpreting the present findings, it is interesting to consider whether the PFC-accumbens neurons that receive synaptic input from DA terminals may have collateral projections to multiple targets. Although earlier studies using electrophysiological methods reported extensive collateralization of PFC pyramidal cell axons to multiple targets (Thierry et al. 1983), recent anatomical studies using retrograde tracers have reported only limited collateralization of PFC-accumbens neurons to either the contralateral PFC, amygdala, or VTA (Pinto et al. 1997). Thus, the modulatory influence mediated by DA on this population of pyramidal neurons is likely to be specific for its projection to the NAc.

In addition to synapsing onto PRV-labeled dendrites, DA ter- minals also formed synaptic contacts onto unlabeled dendrites and spines. It has previously been demonstrated that approximately one-third of DA terminals in the PFC synapse onto the dendrites of GABA-containing local-circuit neurons (Sesack et al. $1995 \mathrm{~b}$ ), and thus it is likely that a portion of the unlabeled dendrites that received synaptic contact from DA terminals in this study arose from this neuronal population. However, it is also likely that a portion of the unlabeled structures that received synaptic input from DA terminals arose from pyramidal neurons that project to regions other than the NAc. This is particularly true for the unlabeled spines contacted by DA terminals, because spines arise almost exclusively from pyramidal neurons (DeFelipe and Fariñas, 1992). The above hypothesis is consistent with in situ hybridization studies reporting mRNA for DA receptors in PFC neurons retrogradely labeled from several projection sites (Gaspar et al. 1995), as well as electrophysiological studies that have observed effects of applied DA or VTA stimulation on PFC neurons that project to areas other than the NAc (Peterson et al. 1987; Godbout et al. 1991). The identity of other populations of PFC pyramidal neurons that receive synaptic input from DA terminals is not known. Possible candidates include cells that project to the contralateral PFC, agranular insular cortex, mediodorsal thalamus and other thalamic nuclei, hypothalamus, amygdala, VTA, and other brainstem areas (Sesack et al. 1989). Moreover, it is possible that DA terminals exhibit a degree of selectivity in their pyramidal neuron targets, similar to data showing a selective innervation of certain classes of local-circuit neurons by DA terminals (Sesack et al. 1995a, 1998). Furthermore, it is possible that DA exerts extrasynaptic influences on PFC pyramidal cell populations in addition to its synaptic actions. Such extrasynaptic mechanisms would be suspected if DA terminals were found not to synapse on pyramidal cell populations that nevertheless expressed receptors for DA. Thus, future examination of both the synaptic targets of DA terminals and the local- 

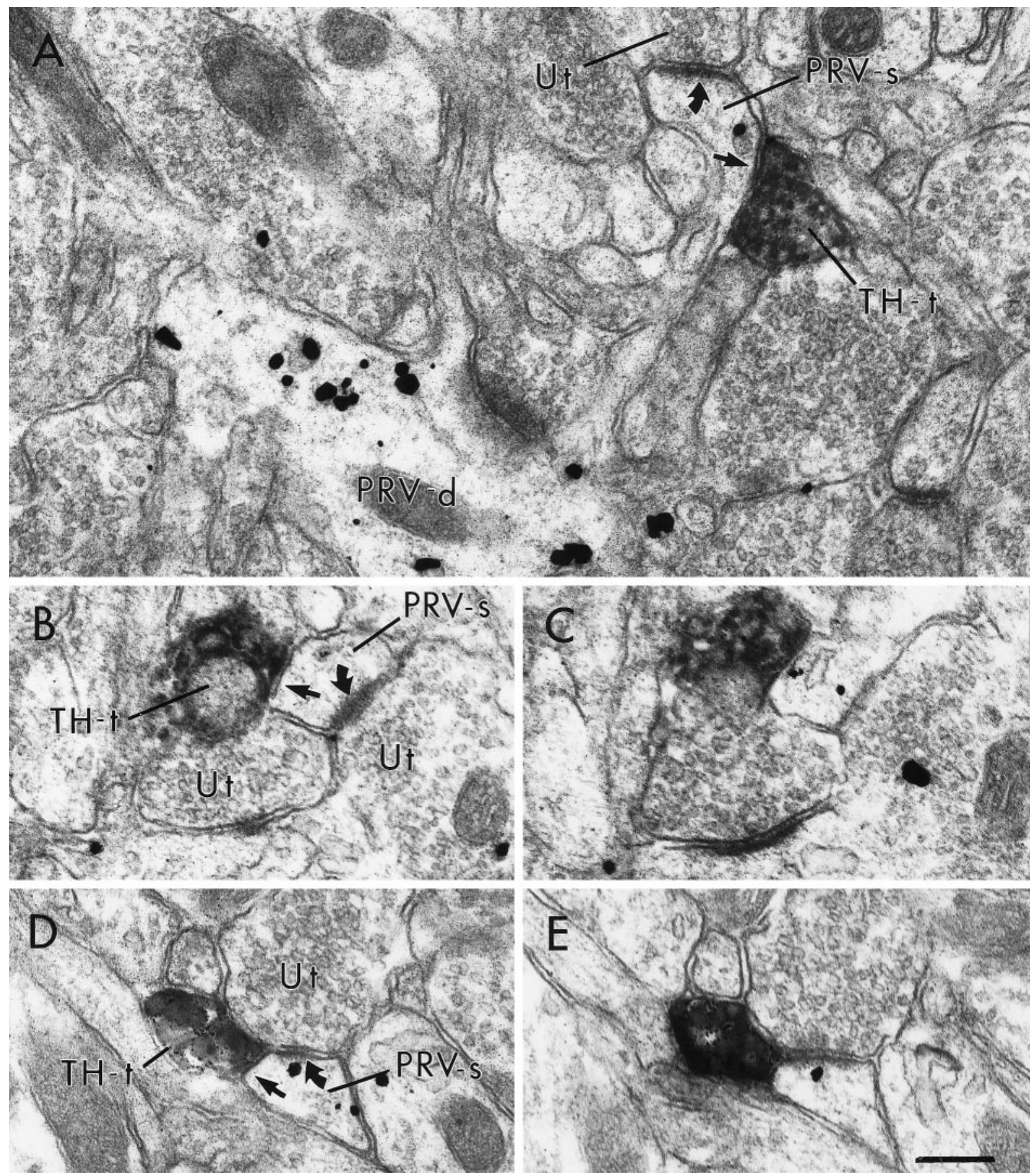

Figure 7. Electron micrographs showing TH-labeled terminals within the PFC directly apposed to PRV-labeled dendritic spines without forming distinct synaptic specializations. In $A$, a PRV-labeled spine ( $P R V$-s) emanates from a dendrite that also contains immunogold labeling for PRV ( $P R V-d)$. The labeled spine receives an asymmetric synapse (curved arrow) from an unlabeled terminal (Ut) and is also contacted (straight arrow) by a TH-labeled terminal $(T H-t)$. Serial sections $(B, C ; D, E)$ illustrate two PRV-labeled spines that receive asymmetric synaptic contact from unlabeled terminals as well as appositional contact from TH-labeled terminals. In $D$ and $E$, the TH-labeled terminal is directly apposed to the unlabeled terminal. Scale bar, $0.25 \mu \mathrm{m}$.

ization of DA receptors will further our understanding of the relative contributions of synaptic and extrasynaptic mechanisms to the overall modulation of PFC neurons by DA.

\section{Technical and functional considerations}

This study represents the first ultrastructural use of a neurotrophic virus to demonstrate a specific afferent that synapses onto an identified population of pyramidal neurons. Thus, in addition to the ability of these tracers to label multisynaptic pathways via trans-synaptic transport, the ability of PRV to extensively fill the dendritic tree of infected first-order neurons provides a powerful tool to examine the synaptic inputs of identified projection neurons. This is particularly important for identification of inputs that target the distal portions of the dendritic tree, which are largely inaccessible to conventional retrograde tracing agents. The use of PRV at the ultrastructural level is especially important 

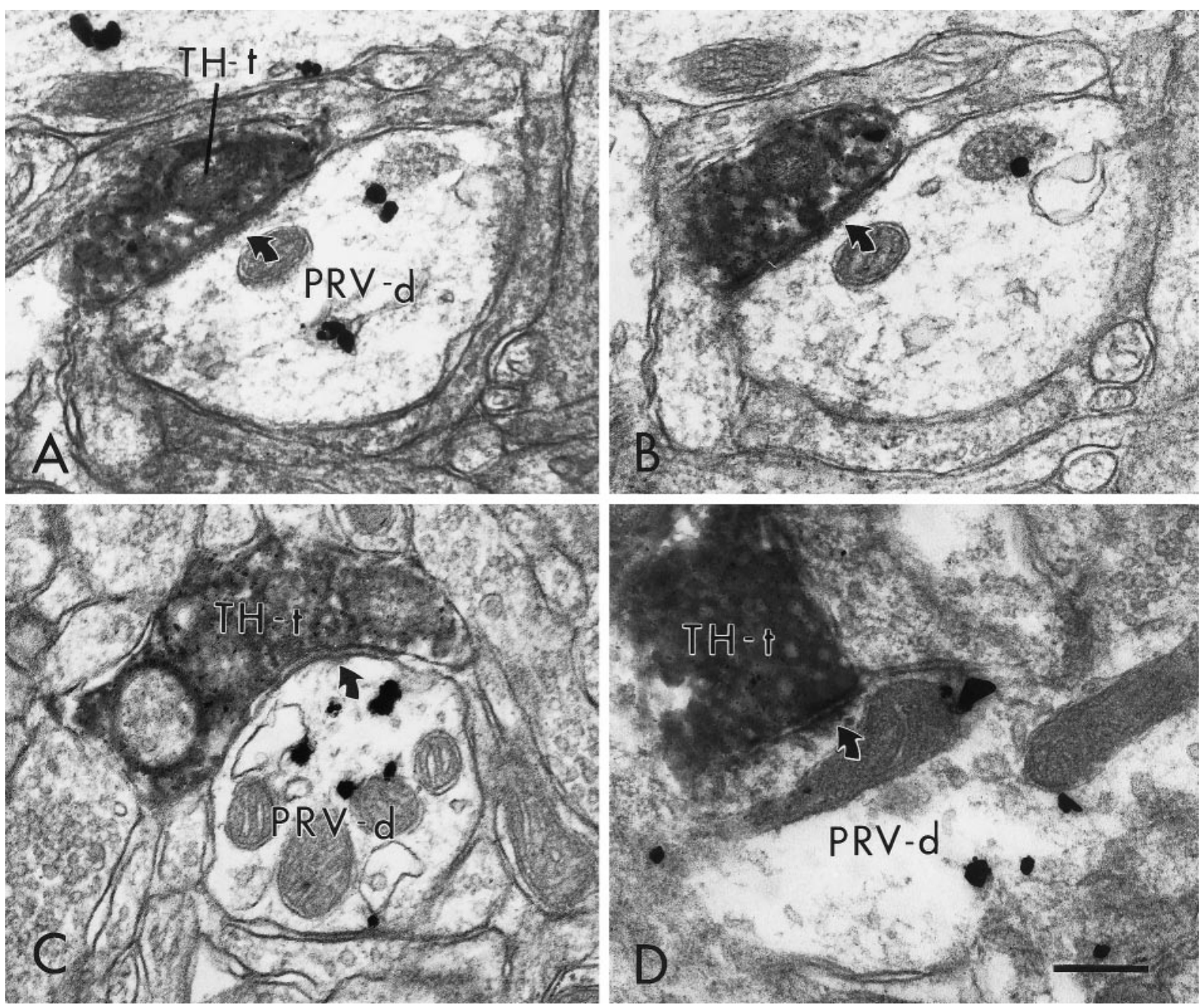

Figure 8. Electron micrographs in the PFC showing TH-labeled terminals that form distinct synaptic contacts with PRV-immunoreactive dendrites. In $A$ and $B$, a TH-labeled terminal (TH-t), shown in serial sections, forms a symmetric synapse (curved arrows) on a PRV-labeled dendrite (PRV-d). $C$ and $D$ show two additional examples of PRV-labeled dendrites that receive symmetric synaptic contact (curved arrows) from TH-labeled terminals. Scale bar, $0.25 \mu \mathrm{m}$.

for examination of circuits for which clear results cannot be obtained by simple temporal analysis of PRV multisynaptic transport. For example, the question of whether DA terminals synapse on PFC-accumbens neurons could not be addressed by light microscopic analysis of trans-synaptic passage of PRV, because VTA DA neurons project directly to the NAc and also to several other nuclei that send afferents to the NAc, such as the paraventricular nucleus of the thalamus (Lindvall and Björklund, 1984; Groenewegen, 1988). Thus, both first- and second-order infection of neurons in the VTA may arise from projections to sites other than the PFC.

These results represent the first direct demonstration of DA synaptic contacts onto an identified class of PFC projection neurons. These synaptic contacts of DA terminals onto the dendritic tree of cortico-accumbens neurons are likely to play an important role in regulating the functional output of cortico-accumbens neurons. This synaptic substrate, along with the convergence of DA and PFC terminals onto common targets within the NAc (Sesack and Pickel, 1992), indicates that DA afferents can modulate cortico-accumbens transmission both at the dendritic as well as the terminal level. These synaptic contacts of DA terminals onto cortico-accumbens neurons may play an important role in the changes in DA transmission within the NAc that have been observed after DA deafferentation in the PFC (Deutch, 1992; King and Finlay, 1995, 1997). Furthermore, given the recent evidence of a reduced density of both DA fibers and receptors in the PFC of schizophrenic patients (Lewis and Akil, 1997; Okubo et al. 1997) it is possible that a loss of DA synaptic input to cortico-accumbens neurons in this disorder may produce secondary changes in DA transmission in subcortical structures.

\section{REFERENCES}

Alexander G, Crutcher M, DeLong M (1990) Basal gangliathalamocortical circuits: parallel substrates for motor, oculomotor, "prefrontal", and "limbic" functions. Prog Brain Res 85:119-146.

Audet MA, Doucet G, Oleskevich S, Descarries L (1988) Quantified regional and laminar distribution of the noradrenaline innervation in the anterior half of adult rat cerebral cortex. J Comp Neurol 274:307-318. 
Bartha A (1961) Experimental reduction of virulence of Aujeszky's disease virus. Magy Allatorv Lapja 16:43-45.

Berger B, Thierry AM, Tassin JP, Moyne MA (1976) Dopaminergic innervation of the rat prefrontal cortex: a fluorescence histochemical study. Brain Res 106:133-145.

Brog J, Salyapongse A, Deutch A, Zahm D (1993) The patterns of afferent innervation of the core and shell in the "accumbens" part of the rat ventral striatum: immunohistochemical detection of retrogradely transported fluoro-gold. J Comp Neurol 338:255-278.

Card JP (1998a) Exploring brain circuitry with neurotrophic viruses: new horizons in neuroanatomy. Anat Rec 253:176-185.

Card JP (1998b) Practical considerations for the use of pseudorabies virus in transneuronal studies of neural circuitry. Neurosci Biobehav Rev 22:685-694.

Card JP, Enquist LW (1994) Use of pseudorabies virus for definition of synaptically linked populations of neurons. In: Methods in molecular genetics (Adolph KW, ed), pp 363-382. New York: Academic.

Carr DB, Sesack SR (1996) Hippocampal afferents to the rat prefrontal cortex: synaptic targets and relation to dopamine terminals. J Comp Neurol 369:1-15.

Cepeda C, Radisavljevic Z, Peacock W, Levine M, Buchwald N (1992) Differential modulation by dopamine of responses evoked by excitatory amino acids in human cortex. Synapse 11:330-341.

Csernansky JG, Murphy GM, Faustman WO (1991) Limbic/mesolimbic connections and the pathogenesis of schizophrenia. Biol Psychiatry 30:383-400.

DeFelipe J, Fariñas I (1992) The pyramidal neuron of the cerebral cortex: morphological and chemical characteristics of the synaptic inputs. Prog Neurobiol 39:563-607.

Descarries L, Lapierre Y (1973) Noradrenergic axon terminals in the cerebral cortex of the rat. I. Radioautographic visualization after topical application of D,L-[3H]norepinephrine. Brain Res 51:141-160.

Descarries L, Umbriaco D (1995) Ultrastructural basis of monoamine and acetylcholine function in CNS. Semin Neurosci 7:309-318.

Descarries L, Lemay B, Doucet G, Berger B (1987) Regional and laminar density of the dopamine innervation in adult rat cerebral cortex. Neuroscience 21:807-824.

Deutch A (1992) The regulation of subcortical dopamine systems by the prefrontal cortex: interactions of central dopamine systems and the pathogenesis of schizophrenia. J Neural Transm 36[Suppl]:61-89.

Enquist LW, Card JP (1996) Pseudorabies virus: a tool for tracing neuronal connections. In: Protocols for gene transfer in neuroscience: towards gene therapy of neurological disorders (Lowenstein PR, Enquist LW, eds), pp 333-348. Chichester: Wiley.

Gaspar P, Bloch B, Le Moine C (1995) D1 and D2 receptor gene expression in the rat frontal cortex: cellular localization in different classes of efferent neurons. Eur J Neurosci 7:1050-1063.

Godbout R, Mantz J, Pirot S, Glowinski J, Thierry A (1991) Inhibitory influence of the mesocortical dopamine neurons on their target cells: electrophysiological and pharmacological characterization. J Pharmacol Exp Ther 258:728-738.

Goldman-Rakic P (1992) Dopamine-mediated mechanisms of the prefrontal cortex. Semin Neurosci 4:149-159.

Goldman-Rakic PS, Leranth C, Williams SM, Mons N, Geffard M (1989) Dopamine synaptic complex with pyramidal neurons in primate cerebral cortex. Proc Natl Acad Sci USA 86:9015-9019.

Grace A (1991) Phasic versus tonic dopamine release and the modulation of dopamine system responsivity: a hypothesis for the etiology of schizophrenia. Neuroscience 41:1-24.

Gray EG (1959) Axo-somatic and axo-dendritic synapses of the cerebral cortex: an electron microscope study. J Anat 93:420-433.

Groenewegen HJ (1988) Organization of the afferent connections of the mediodorsal thalamic nucleus in the rat, related to the mediodorsalprefrontal topography. Neuroscience 24:379-431.

Groenewegen HJ, Berendse HW (1994) Anatomical relationships between the prefrontal cortex and the basal ganglia in the rat. In: Motor and cognitive functions of the prefrontal cortex (Thierry A-M, Glowinski J, Goldman-Rakic PS, Cristen Y, eds), pp 51-77. Berlin: Springer. Groenewegen H, Berendse H, Wolters J, Lohman A (1990) The anatomical relationship of the prefrontal cortex with the striatopallidal system, the thalamus and the amygdala: evidence for a parallel organization. Prog Brain Res 85:95-116.

Harvey J, Lacey MG (1996) Endogenous and exogenous dopamine depress EPSCs in rat nucleus accumbens in vitro via $\mathrm{D}_{1}$ receptor activation. J Physiol (Lond) 492:143-154.
Jay TM, Glowinski J, Thierry AM (1995) Inhibition of hippocampoprefrontal cortex excitatory responses by the mesocortical DA system. NeuroReport 6:1845-1848.

King D, Finlay J (1995) Effects of selective dopamine depletion in medial prefrontal cortex on basal and evoked extracellular dopamine in neostriatum. Brain Res 685:117-128.

King D, Finlay JM (1997) Loss of dopamine terminals in the medial prefrontal cortex increased the ratio of DOPAC to DA in tissue of the nucleus accumbens shell-role of stress. Brain Res 767:192-200.

Krettek JE, Price JL (1977) The cortical projections of the mediodorsal nucleus and adjacent thalamic nuclei in the rat. J Comp Neurol 171:157-192.

Krimer LS, Jakab RL, Goldman-Rakic PS (1997) Quantitative threedimensional analysis of the catecholaminergic innervation of identified neurons in the macaque prefrontal cortex. J Neurosci 17:7450-7461.

Leranth C, Pickel V (1989) Electron microscopic preembedding doubleimmunostaining methods. In: Neuroanatomical tract tracing methods 2 : recent progress (Heimer L, Záborszky L, eds), pp 129-172. New York: Plenum.

Lewis DA, Akil M (1997) Cortical dopamine in schizophrenia: strategies for postmortem studies. J Psychiatry Res 31:175-195.

Lewis DA, Sesack SR (1997) Dopamine systems in the primate brain. In: Handbook of chemical neuroanatomy: the primate nervous system, Part 1 (Bloom FE, Björklund A, Hökfelt T, eds), pp 261-373. Amsterdam: Elsevier.

Lindvall O, Björklund A (1984) General organization of cortical monoamine systems. In: Monoamine innervation of the cerebral cortex (Descarries L, Reader T, Jasper H, eds), pp 9-40. New York: Liss.

McGeorge A, Faull R (1989) The organization of the projection from the cerebral cortex to the striatum in the rat. Neuroscience 29:503-537.

O'Donnell P, Grace A (1994) Tonic $\mathrm{D}_{2}$-mediated attenuation of cortical excitation in nucleus accumbens neurons recorded in vitro. Brain Res 634:105-112.

O'Donnell P, Lavin A, Enquist LW, Grace AA, Card JP (1997) Interconnected parallel circuits between rat nucleus accumbens and thalamus revealed by retrograde transynaptic transport of pseudorabies virus. J Neurosci 17:2143-2167.

Okubo Y, Suhara T, Suzuki K, Kobayashi K, Inoue O, Terasaki O, Someya Y, Sassa T, Sudo Y, Matsushima E, Iyo M, Tateno Y, Toru M (1997) Decreased prefrontal dopamine D1 receptors in schizophrenia revealed by PET. Nature 385:634-636.

Paxinos G, Watson C (1986) The rat brain in stereotaxic coordinates, Ed 2. New York: Academic.

Peters A, Palay SL, Webster H (1991) The fine structure of the nervous system: neurons and their supporting cells, Ed 3. New York: Oxford.

Peterson O, St. Mary J, Harding N (1987) Cis-flupentixol antagonism of the rat prefrontal cortex neuronal response to apomorphine and ventral tegmental area input. Brain Res Bull 18:723-729.

Pinto AO, Miner LAH, Sesack SR (1997) Limited collateralization of prefrontal cortical neurons projecting to the nucleus accumbens and contralateral prefrontal cortex in the rat. Soc Neurosci Abstr 23:901.

Séguéla P, Watkins KC, Descarries L (1988) Ultrastructural features of dopamine axon terminals in the anteromedial and the suprarhinal cortex of adult rat. Brain Res 442:11-22.

Séguéla P, Watkins KC, Geffard M, Descarries L (1990) Noradrenaline axon terminals in adult rat neocortex: an immunocytochemical analysis in serial thin sections. Neuroscience 35:249-264.

Sesack SR, Pickel VM (1992) Prefrontal cortical efferents in the rat synapse on unlabeled neuronal targets of catecholamine terminals in the nucleus accumbens septi and on dopamine neurons in the ventral tegmental area. J Comp Neurol 320:145-160.

Sesack SR, Deutch AY, Roth RH, Bunney BS (1989) Topographical organization of the efferent projections of the medial prefrontal cortex in the rat: an anterograde tract-tracing study with Phaseolus vulgaris leucoagglutinin. J Comp Neurol 290:213-242.

Sesack SR, Bressler CN, Lewis DA (1995a) Ultrastructural associations between dopamine terminals and local circuit neurons in the monkey prefrontal cortex: a study of calretinin-immunoreactive cells. Neurosci Lett 200:9-12.

Sesack SR, Snyder CL, Lewis DA (1995b) Axon terminals immunolabeled for dopamine or tyrosine hydroxylase synapse on GABAimmunoreactive dendrites in rat and monkey cortex. J Comp Neurol 363:264-280.

Sesack SR, Melchitzky DS, Lewis DA (1998) Dopamine innervation of a subclass of local circuit neurons in monkey prefrontal cortex: ultra- 
structural analysis of tyrosine hydroxylase and parvalbumin immunoreactive neurons. Cereb Cortex 8:614-622.

Smiley J, Levey A, Ciliax B, Goldman-Rakic P (1994) $\mathrm{D}_{1}$ dopamine receptor immunoreactivity in human and monkey cerebral cortex: predominant and extrasynaptic localization in dendritic spines. Proc Natl Acad Sci USA 91:5720-5724.

Smiley JF, Goldman-Rakic PS (1993) Heterogeneous targets of dopamine synapses in monkey prefrontal cortex demonstrated by serial section electron microscopy: a laminar analysis using the silverenhanced diaminobenzidine sulfide (SEDS) immunolabeling technique. Cereb Cortex 3:223-238.

Thierry A, Chevalier G, Ferron A, Glowinski J (1983) Diencephalic and mesencephalic efferents of the medial prefrontal cortex in the rat: Electrophysiological evidence for the existence of branched axons. Exp Brain Res 50:275-282.
Vahlne A, Nystrom B, Sandberg M, Hamberger A, Lycke E (1978) Attachment of herpes simplex virus to neurons and glial cells. J Gen Virol 40:359-371.

Vahlne A, Svennerholm B, Sandberg M, Hamberger A, Lycke E (1980) Differences in attachment between herpes simplex type 1 and type 2 virus to neurons and glial cells. Infect Immun 28:675-680.

Van Eden C, Hoorneman E, Buijs R, Matthijssen M, Geffard M, Uylings $H$ (1987) Immunocytochemical localization of dopamine in the prefrontal cortex of the rat at the light and electron microscopic level. Neuroscience 22:849-862.

Weinberger DR (1987) Implications of normal brain development for the pathogenesis of schizophrenia. Arch Gen Psychiatry 44:660-669.

Yang CR, Seemans JK (1996) Dopamine D1 receptor actions in layers V-VI rat prefrontal cortex neurons in vitro: modulation of dendriticsomatic signal integration. J Neurosci 16:1922-1935. 